\title{
Contemporary Chinese Art Design from the Perspective of National Culture
}

\author{
Xiangxin Wei \\ Arts Department, Shandong Agriculture Engineering University, Ji'nan, 250100, China
}

Keywords: Art design. National culture. Main application points

\begin{abstract}
In the context of continuous development of art design, it can be easily discovered that today's art design mainly imitates foreign works of art, and lacks use of traditional Chinese national culture elements. For a long period of time, Chinese art design has been lacking independent creativity, and thus its healthy development is hindered. Art is a comprehensive discipline, and is a specific performance with profound cultural connotation formed by development status of contemporary society combined with characteristics of national development. In this context, this paper briefly discusses about problems in contemporary art design, analyzes artistic value of national culture, and proposes several main application points and means of expression, in order to perfect modern art design and enrich Chinese elements in design.
\end{abstract}

\section{Problems in contemporary art design}

\section{Lack of educational concepts}

In recent decades, the demand of art design talents increases with the development of design market and social environment, and thus drives the development of the so-called art education industry. However, in terms of China's current art education status, education is mostly carried out in colleges, while "art talents" are selected in high schools. The majority of students finally choose art major not because of enthusiasm for art, but because of unsatisfactory examination results, hoping to be admitted to a better university with the strength of art. Therefore, few of these students would be engaged in relevant industries after graduation from colleges. With a growing number of students applying for art and music majors, college art education becomes gradually modeled, and it is less possible to train art talents by four-year short-term education. Therefore, China shall perfect educational concepts, and allow students who are really interested and capable to receive professional art training and make contribution to Chinese art design.

Besides, Chinese art education has not reached a mature stage. Under the influence of western thoughts, neither blind refusal nor blind worship are driving forces to promote the development of Chinese art design, and current prevailing Chinese art education is carried out under the guidance of interests of market value. Education is an initial stage of talent training, and is also a process of long-term development. In terms of education of contemporary art design, China shall learn rationally from western cultures, attach importance to and use national culture in education, change traditional unitary mode, acquire and integrate resources from culture, and thus carry Chinese national culture forward in art design by combining Chinese and western elements.

\section{Failure to master real demands}

In modern society, a variety of commodities occur in front of people, and dazzling advertising makes modern people have long been away from states of lack of traditional substance and purchasing by solely relying on product quality and prices, which are replaced by advertising art design based on quality. The modern era is homogenous. For example, when two stores sell the same commodities with the same quality and prices, most people would choose those with better product design and appearance. Therefore, modern society has no longer been an era of commodity marketing, but the era of design marketing.

In terms of contemporary Chinese art design mode, the lack of national elements is mainly because of unfamiliarity with product cognition and failure to apply national elements successfully to product design. Design is not only about visual presentation, but also a series of sensory designs including 
tactile and olfactory feelings. People accept design connotation and cultural characteristics while accepting products. National culture is indispensable in modern design, and is the basis of modern culture, and extends modern culture to have a long life.

\section{Simple use of national elements}

With today's continuous development of Chinese art design, Chinese elements occur in a variety of art design evaluation. The use of national culture in various types of art design is still in the stage of continuous development, and is gradually reflected in society, culture and business.

It is good to apply national culture to contemporary design, the success or failure of works of art depends on whether national elements are applied appropriately or not. Some designers ignore the degree of effective use although they know the importance of national culture in design. Although Visual impacts can indeed be achieved within a certain period of time by attracting people with only representative Chinese elements or national symbols, such works of art would not be classic and could only be defined as dependency of trend of the times.

The use of national elements shall be based on a full understanding of the content to be expressed and context in which objects are to be designed, and perceive proper elements through researches. To simply achieve visual effects within a certain period of time, works of art with a lack of vitality would be created by embezzling simply elements of national culture while ignoring cultural connotation.

\section{Value of national culture in contemporary art design}

Art design is a synthesis of the times, creativity, humanity and artistry, and is a combination of marginality with intersection. Art design is designers' in-depth exploration of design objects, conveying creators' inner feelings and consciousness and expressing effectively national characteristics and characteristics of the times. Thousands of years of cultural heritage of China leave a huge cultural wealth, gathering different characteristics of Chinese art and providing lots of creation elements for contemporary art design.

Rational use of national culture in contemporary art design is a combination of artistry with humanity, and is source and driving force of spiritual strength. Works designed by artists not only reflect geographical characteristics, but also symbolize the development of Chinese art in contemporary art context. At this stage, Chinese art design needs a number of design works with Chinese national cultural characteristics, which combine historical contexts with reality effectively and realize exchanges with international design works. Chinese art design refers to Chinese properties in modern art instead of oriental imagination. To make Chinese national cultures punchline of works of art in world, there shall be works of art with rich connotation and full reflection of Chinese properties. Asian people have unique ways of thinking, while China has unique national cultures. The use of national culture in contemporary art design is the best way to make the world feel and understand oriental beauty.

\section{Main application points of national culture in contemporary art design}

\section{Visual design}

Visual design is the first impression that works of art leave to people, and thus people have views or evaluation. Art design itself is an integrated discipline which focuses on visual appreciation, forms of beauty, visual effects and decorative effects. Therefore, application of national culture to design shall begin with traditional culture and national culture, so that works of art have strong visual impacts and thus carry excellent national cultures forward according to national demands.

With a variety of Chinese national culture, there are many elements for reference. To design works with national culture under thousands of years of cultural heritage, designers shall extract traditional culture, excavate profound expression connotation by discarding the dross and selecting the essence, and express historical information and national culture visually to achieve the purpose of shocking the mind under visual impacts. 


\section{Conceptual design}

Visual impacts are only a part of expression effects of works of art, and the most important part of works of art is the connotation. To integrate national culture into design concepts, cultural expressions of contemporary art design shall be integrated into in-depth researches, and promote national art design to the level of thoughts. Only under the guidance of this design concept, can works of art truly express vitality, regard national culture as the foundation of development, get rid of traditional habit of blind reference, and truly realize the importance of national culture in contemporary art design.

\section{Means of expression of national culture in art design}

\section{Expression of national characters}

In the world culture, hieroglyphs in Chinese national culture are the most featured among all characters. Hieroglyphs describe simple things to people in the way of obtaining image from analogy, and evolve and change constantly over thousands of years of development of the Chinese nation, and retain traditional culture effectively. The expression of Chinese characters includes hieroglyphic, phonetic loan, self-explanatory, mutually explanatory, ideograph and phonogram etc, which have become systematic and standardized over thousands of years of development and have developed into a number of means of expression. After the occurrence of printing, national characters achieve a combination of standardization and artistic beauty, and a variety of modern fonts meet people's demands for language and words.

In terms of art design, the art connotation can be expressed by rational use of national characters through cadence. Font design is also important in expression of contemporary art. For example, in advertising art design, expression of characters can effectively reflect product types and connotation etc, and attract consumers compared with ordinary character design. With intensifying market competition, it has been common to use character art in advertising design, and character art has been added to logos of some enterprises. Under changes of fonts and forms, designers integrate art design into Chinese symbols and characters capably, so that national characteristics are fully reflected on the premise of reflecting design content. Art design of national characters can enrich design expressive force, and reflect design function with a simple, vivid and accurate visual sense.

\section{Expression of national colors}

Each country has its representative colors, like white and black for Germany, blue and red for the United States, and red on China's national flag for China.

National colors are formed autonomously after long-term development, and belong to historical and aesthetic heritage. According to researches, red has long been a representative color of China, or red is a symbolic color. In excavation of Beijing cavemen, archaeologists find that bodies of cavemen are covered by a layer of red powder, and decorations have been rendered by hematite. Although red maybe means bright-colored physiological reactions for these hominids, this color represents certain hope or power. Red reflects and symbolizes warmth and hotness in national culture, and thus is pursued by China for a long time and is widely used in today's art design.

For example, in traditional Chinese festival-Spring Festival, red Chinese knots, red couplets, red balloons and red flags all reflect designers' pursuit of red. In contemporary art design, there is a small number of design works with reflect Chinese red, and these works are centralized in the Spring Festival. Designers shall increase the use of Chinese national color, and spread Chinese red all over the world.

Besides red, yellow is also one of favorite colors of the Chinese since ancient times. For example, symbolic color of emperors and color of stars on China's national flag are all yellow. This is not only because yellow symbolizes power and wealth, but also because of race of the Chinese. The Yellow River, yellow earth and yellow race are integrated into one, making yellow one of Chinese national colors.

\section{Expression of comprehensive culture}


Because of long history of China and a variety of forms of expression of national culture, there are lots of national cultures with a sense of art, such as religious art, literature and art, drama art, music art and folk art etc. Comprehensive art includes all aspects of Chinese national culture, and has countless representative works, and thus could be successfully presented in modern art design.

In terms of Chinese contemporary art design models, some designers have begun to focus on national elements and design works with traditional Chinese characteristics. For example, some designers integrate Chinese paper cutting culture into the design of calendars, with a lifelike paper cutting work on each page. Although such calendars are a little expensive, many people would buy because of memory and collection values of the attached works. Chinese pottery and porcelain culture and embroidery culture have been carried forward gradually in art design under long-term development. By combining with contemporary art and attaching modern painting art to potteries, current traditional Chinese pottery and porcelain arouse strong response in international markets. Embroidery culture is mostly reflected in TV plays or films. Embroidery elements are reflected in contemporary art design in the form of graphic design due to its too profound techniques. With the development of designers' innovative thinking, cross-stitch occur, and this simple work of art makes more people know about Chinese national culture and thus become strongly interested. Along with the development of cross-stitch, ribbon embroidery and silk embroidery become popular currently, making great contribution to the spread of embroidery culture. Combination of a variety of national culture in art design is a higher level of art, and thus traditional Chinese culture is carried forward.

\section{Conclusions}

Historical elements with characteristics of the times show unique artistic charm in contemporary art design field, attracting oriental and western designers to explore, and bring more exchanges about world culture, and give more inspiration to contemporary art design. By analyzing the application of national elements in Chinese modern art design, China has deficiencies of excessive imitation and lack of vitality in design. Chinese art designers shall make full use of Chinese national elements, and use culture comprehensively in terms of national colors and characters etc, refer rationally to long-standing and well-established cultures, and thus create art design works with rich national elements.

\section{References}

[1] Han Yayi. The Innovation of Contemporary Art Design and the Traditional Cultural Heritage [J]. Journal of Changchun University of Science and Technology: Social Sciences Edition, 2010 (05).

[2] Shi Yuanwu, Zhu Huaxin. Discussion on the Application of Traditional Chinese Colors in Contemporary Art Design Teaching [J]. Artscircle, 2010 (09).

[3] Liu Meihua. Inspiration of Traditional Teaching Concepts for Contemporary Art Design Education [J]. Art, 2013 (01).

[4] Yue Chanjun, Xu Mingxia. The Marketing Communications of Element of Traditional Culture in the Modern Art and Design [J]. Northern Economy and Trade, 2012 (02). 